\title{
Availability of Breast Milk for Preterm Neonates by Gestational Age during NICU Stay
}

\author{
Santosh Kumar Panda1(10 \\ Kalpita Sahoo ${ }^{2}$ \\ ${ }^{1}$ Department of Paediatrics, Kalinga Institute of Medical Sciences, \\ Kalinga Institute of Industrial Technology, Bhubaneswar, Odisha, \\ India \\ 2 Department of Paediatrics, Institute of Medical Sciences and Sum \\ Hospital, Siksha 'O' Anusandhan, Bhubaneswar, Odisha, India \\ ${ }^{3}$ School of Public Health, Kalinga Institute of Industrial Technology, \\ Bhubaneswar, Odisha, India
}

J Child Sci 2021;11:e227-e232.

\author{
Avantika Dhanawat ${ }^{1}$
}

\begin{abstract}
Keywords

- neonate

- preterm birth

- nutrition

- human milk

The objective of this study was to explore the availability of expressed breast milk (EBM) volume for the premature neonates born from mothers in different gestational age groups during neonatal intensive care unit (NICU) stay. All preterm infants (extremepreterm infant [EPTI, $<28$ weeks], very-preterm infant [VPTI, 28-316/7 weeks], and moderate-preterm infant [MPTI, 32-33/7 weeks]) and their mothers were included in the study. Infants not receiving mother's own milk and neonates deceased or discharged against medical advice, and the mother with illness during postpartum period were excluded from the study. A predesigned tool was used to collect information on maternal characteristics, neonatal characteristics, and milk diary for preterm neonates from the NICU case records. The primary outcome variable EBM volume available on day 7 was compared across three gestational groups. Logistic regression was used to predict EBM availability. A total of 78 preterm neonates, including $10 \mathrm{EPTI}, 37 \mathrm{VPTI}$, and $31 \mathrm{MPTI}$, had average birth weight of $962.5 \pm 228.25,1,185.1 \pm 183.14$, and $1,293.2 \pm 182.92 \mathrm{~g}$, respectively. Receipt of exclusive breast milk among EPTI, VPTI, and MPTI was 80,94 , and $83.8 \%$, respectively. Maternal characteristics were similar except for the mode of conception $(p=0.001)$, mode of delivery $(p=0.04)$, and antenatal steroid exposure $(p=0.02)$ among three gestational categories. The median (Q1-Q3) volume of EBM on day 7 were 160 (136.3-202.5), 150 (140-187.5), and 160 (150-220) $\mathrm{mL}$ for EPTI, VPTI, and MPTI neonates, respectively, without any statistical significance. Regression analysis suggests no effect of gestational age on EBM availability. The feasibility of mother's own milk use for extremely preterm neonates is similar to higher gestational preterm neonates.
\end{abstract}

\begin{abstract}
Address for correspondence Santosh Kumar Panda, MD, DNB, Department of Paediatrics, Kalinga Institute of Medical Sciences, Kalinga Institute of Industrial Technology, Bhubaneswar 751024, Odisha, India (e-mail: doc.sant@yahoo.co.in; santosh.panda@kims.ac.in).
\end{abstract}

\section{Introduction}

Prematurity is one of the leading causes of neonatal mortality worldwide. ${ }^{1}$ Mother's own milk is the recommended enteral nutrition for preterm neonate and pasteurized donor milk is recommended in its absence. ${ }^{2}$ Preterm neonates receive lesser amount of breast milk in initial days compared with term neonates secondary to physiological immaturity and pathological morbidities. The necrotizing enterocolitis and feed intolerance in preterm neonates are inversely received

January 19, 2021

accepted after revision

July 17, 2021
DOI https://doi.org/

$10.1055 / \mathrm{s}-0041-1735534$.

ISSN 2474-5871. (c) 2021. The Author(s).

This is an open access article published by Thieme under the terms of the Creative Commons Attribution License, permitting unrestricted use, distribution, and reproduction so long as the original work is properly cited. (https://creativecommons.org/licenses/by/4.0/)

Georg Thieme Verlag KG, Rüdigerstraße 14, 70469 Stuttgart, Germany 
related to gestational age and birth weight, and could be protected by mother's own milk. ${ }^{3}$ Aggressive enteral nutrition practice has significantly cut down the need of central line, total parenteral nutrition, late-onset sepsis, and extrauterine growth restriction. ${ }^{4}$ The average duration to reach full enteral nutrition among very low birth weight (VLBW) neonates is 7 to 10 days. ${ }^{5}$ Premature delivery impairs the phase of lactogenesis II, leading to insufficient milk for preterm neonates for aggressive enteral nutrition. ${ }^{6}$ Maternal characteristics such as mode of delivery, mode of conception, and antenatal steroid are known confounders for the availability of expressed breast milk (EBM) in preterm mothers. $^{7-9}$ In this context, the present study explores the availability of breast milk volume for preterm neonates by gestational age of maternal delivery.

\section{Methods}

This is a hospital-based review of case records of inborn preterm neonates admitted to neonatal intensive care unit (NICU) from February 2019 to October 2019. All inborn preterm (extreme-preterm infant [EPTI] [ $<28$ weeks], very-preterm infant [VPTI] [28-316/7 weeks], and moderate-preterm infant [MPTI] [32-33 $3^{6 / 7}$ weeks]) neonates delivered less than 34 weeks were included in the study. Infants not receiving mother's own milk and neonates deceased or discharged against medical advice or maternal illness where mother admitted to intensive care due to postpartum complication, and breast milk expression was not possible in initial 48 hours were excluded from the study. As per hospital policy, pregnant mothers admitted in expectant delivery before 34 weeks were given antenatal counseling and the perinatal team took the responsibility of preterm delivery care. Maternal age, parity, mode of conception, presence of antenatal Doppler, presence of oligohydramnios, antepartum hemorrhage, maternal illnesses, antenatal steroid administration, and mode of delivery were recorded from the antenatal history of neonatal case records. Mothers expressing breast milk were supported by dedicated neonatal sisters and junior residents under supervision of neonatologist. Mothers and family members were encouraged to initiate manual milk expression from first contact and importance of breast milk always prioritized. In case of inadequacy of mother's own milk, galactagogue (tablet domperidone $10 \mathrm{mg}$ thrice daily for 2 weeks) and breast pump were advised by treating physician to augment milk production. Kangaroo mother care (KMC) was a standard protocol, universally practiced for all preterm neonates after critical illness was over. The available EBM (the milk volume produced by mother) per day was recorded in neonatal nursing charts and was used for encouragement of milk expression during daily family counseling. Neonatal gestational age was assigned based on maternal last menstrual period, expected time of delivery from first trimester ultrasound, and modified new Ballard scoring. Timing of initiation of trophic feeding and advancement of enteral nutrition were implemented by treating neonatologist based on NICU protocol. Full enteral feeding attainment was defined by the stoppage of parenteral nutrition and achievement of $120 \mathrm{~mL} / \mathrm{kg} / \mathrm{d}$ of enteral nutrition. Both maternal and neonatal variables were described as descriptive statistics, that is, mean \pm standard deviation (SD), median (Q1-Q3), and frequency (\%). Categorical variables were analyzed by chi-square/Fisher's exact test. The primary outcome variable, that is, EBM volume available on day 7 was compared across three gestational groups by Kruskal-Wallis' nonparametric test. The median value was used to categorize seventh day EBM volume into two groups, that is, $<156$ and $\geq 156 \mathrm{~mL}$ volume. Multivariable binomial logistic regression analysis was done to model the effect of gestational age on EBM on day 7 availability above median volume. SPSS (version 20 IBM) was used for data analysis.

\section{Results}

Out of 84 inborn preterm neonates, 5 neonates died and 1 neonate was on formula feeding due to maternal death. Total 78 preterm neonates were studied comprising $10(12.82 \%)$ EPTI, 37 (47.44\%) VPTI, and 31 (39.74\%) MPTI with mean ( \pm SD) birth weight $(\mathrm{kg})$ were $0.96 \pm 0.23,1.19 \pm 0.18$, and $1.29 \pm 0.18$, respectively. The demographic profile of maternal characteristics across three gestational groups is given in - Table 1. The three groups of mothers were similar in their characteristics except for the mode of maternal conception, antenatal steroid coverage, and mode of delivery. Mothers in the EPTI group had a lower rate of cesarean section $2 / 10(20 \%)$ in comparison to $23 / 37(62.1 \%)$ in VPTI and 20/31 (64.5\%) MPTI groups. The antenatal steroid exposure of EPTI, VPTI, and MPTI groups were 5/10 (50\%), 17/37 (45.94\%) and 24/31 (77.4\%), respectively.

The receipt of breast milk stratified by gestational age groups among preterm neonates is shown in - Fig. 1. In this study, 8 of 10 (80\%) EPTI, 35 of 37 (94.59\%) VPTI, and 26 of 31 (83.87\%) MPTI had received only express breast milk during NICU stay and rest were on mixed feeding (breast milk plus formula feeding). Neonatal characteristics of each group of preterm neonates including enteral nutrition are shown in -Table 2. The median (Q1-Q3) EBM volume on day 2 (EPTI: 14 [0-18.25] mL, VPTI: 15 [10-24.5] mL, and MPTI: -16 [11-25] mL), day 7 (EPTI: 160 [136.3-202.5] mL, VPTI: 150 [140-187.5] mL, and MPTI: 160 [150-220] mL), and at NICU discharge (EPTI: 257.5 [175-280] mL, VPTI: 300 [260-320] $\mathrm{mL}$, and MPTI: 270 [190-290] $\mathrm{mL}$ ) were not significantly different across different gestational age groups (-Fig. 2).

The EBM availability on day 7 was not significantly different across gestational age groups after matching for the confounders ( - Table 3 ).

\section{Discussion}

In perinatal care practice, supportive of breast milk availability for preterm neonates from the very beginning should be on evidence-based policies and family centered. ${ }^{10,11}$ In a developing country, there is a lack of availability in pasteurized donor breast milk and human milk banking facility and formula feeding being used as the alternative enteral nutrition in absence of mother's own milk. ${ }^{12}$ To our knowledge, 
Table 1 Maternal characteristics stratified by preterm gestational age groups

\begin{tabular}{|c|c|c|c|c|c|}
\hline \multicolumn{2}{|l|}{ Maternal characteristics } & $\begin{array}{l}\text { Extreme preterm } \\
(N=10)\end{array}$ & $\begin{array}{l}\text { Very preterm } \\
(N=37)\end{array}$ & $\begin{array}{l}\text { Moderate preterm } \\
(N=31)\end{array}$ & p-Value \\
\hline \multicolumn{2}{|l|}{$\begin{array}{l}\text { Age of mother }(y) \text {, mean } \\
{[95 \% \mathrm{Cl}] \pm S D}\end{array}$} & $\begin{array}{l}31.4(29.5-33.3) \pm \\
2.7\end{array}$ & $\begin{array}{l}28.9(27.3-30.4) \pm \\
4.6\end{array}$ & $\begin{array}{l}28(25.8-30.2) \pm \\
5.9\end{array}$ & 0.187 \\
\hline \multirow[t]{2}{*}{ Parity } & Primi & $7(70.00 \%)$ & $19(51.35 \%)$ & $22(71.00 \%)$ & \multirow[t]{2}{*}{0.227} \\
\hline & Multi & $3(30.00 \%)$ & $18(48.65 \%)$ & $9(29.00 \%)$ & \\
\hline \multirow{2}{*}{$\begin{array}{l}\text { Assisted reproductive } \\
\text { technique for conception }\end{array}$} & No & $6(60.00 \%)$ & $34(91.90 \%)$ & $31(100.00 \%)$ & \multirow[t]{2}{*}{0.001} \\
\hline & Yes & $4(40.00 \%)$ & $3(8.10 \%)$ & $0(0.00 \%)$ & \\
\hline \multirow{2}{*}{$\begin{array}{l}\text { Singleton or multiple } \\
\text { pregnancy }\end{array}$} & Singleton & $6(60.00 \%)$ & $22(59.45 \%)$ & $21(67.70 \%)$ & \multirow[t]{2}{*}{0.762} \\
\hline & Multiple & $4(40.00 \%)$ & $15(40.55 \%)$ & $10(32.30 \%)$ & \\
\hline \multirow{2}{*}{$\begin{array}{l}\text { Maternal gestational } \\
\text { diabetes mellitus }\end{array}$} & No & $10(100.00 \%)$ & $33(89.20 \%)$ & $28(90.30 \%)$ & \multirow[t]{2}{*}{0.752} \\
\hline & Yes & $0(0.00 \%)$ & $4(10.80 \%)$ & $3(9.70 \%)$ & \\
\hline \multirow[t]{2}{*}{ Maternal hypertension } & No & $7(70.00 \%)$ & 34 (91.90\%) & $26(83.90 \%)$ & \multirow[t]{2}{*}{0.133} \\
\hline & Yes & $3(30.00 \%)$ & $3(8.10 \%)$ & $5(16.10 \%)$ & \\
\hline \multirow[t]{2}{*}{ Hypothyroidism } & No & $10(100.00 \%)$ & $31(83.80 \%)$ & $27(87.10 \%)$ & \multirow[t]{2}{*}{0.516} \\
\hline & Yes & $0(0.00 \%)$ & $6(16.20 \%)$ & $4(12.90 \%)$ & \\
\hline \multirow[t]{2}{*}{ Cardiorespiratory illness } & No & $10(100.00 \%)$ & $36(97.30 \%)$ & $30(96.80 \%)$ & \multirow[t]{2}{*}{0.999} \\
\hline & Yes & $0(0.00 \%)$ & $1(2.70 \%)$ & $1(3.20 \%)$ & \\
\hline \multirow{2}{*}{$\begin{array}{l}\text { Premature rupture } \\
\text { of membrane }\end{array}$} & No & $10(100.00 \%)$ & $25(67.60 \%)$ & $24(77.40 \%)$ & \multirow[t]{2}{*}{0.091} \\
\hline & Yes & $0(0.00 \%)$ & $12(32.40 \%)$ & $7(22.60 \%)$ & \\
\hline \multirow[t]{2}{*}{ Oligohydramnios } & No & $10(100.00 \%)$ & $36(97.30 \%)$ & $28(90.30 \%)$ & \multirow[t]{2}{*}{0.349} \\
\hline & Yes & $0(0.00 \%)$ & $1(2.70 \%)$ & $3(9.70 \%)$ & \\
\hline \multirow{2}{*}{$\begin{array}{l}\text { Antenatal abnormal } \\
\text { Doppler }\end{array}$} & No & $9(90.00 \%)$ & $36(97.30 \%)$ & $29(93.50 \%)$ & \multirow[t]{2}{*}{0.469} \\
\hline & Yes & $1(10.00 \%)$ & $1(2.70 \%)$ & $2(6.50 \%)$ & \\
\hline \multirow[t]{2}{*}{ Antepartum hemorrhage } & No & $10(100.00 \%)$ & $36(97.30 \%)$ & $28(90.30 \%)$ & \multirow[t]{2}{*}{0.349} \\
\hline & Yes & $0(0.00 \%)$ & $1(2.70 \%)$ & $3(9.70 \%)$ & \\
\hline \multirow[t]{2}{*}{ Antenatal steroid } & No & $5(50.00 \%)$ & $20(54.05 \%)$ & $7(22.60 \%)$ & \multirow[t]{2}{*}{0.022} \\
\hline & Yes & $5(50.00 \%)$ & 17 (45.95\%) & $24(77.40 \%)$ & \\
\hline \multirow[t]{2}{*}{ Mode of delivery } & Vaginal & $8(80.00 \%)$ & $14(37.90 \%)$ & $11(35.50 \%)$ & \multirow[t]{2}{*}{0.04} \\
\hline & Cesarean section & $2(20.00 \%)$ & $23(62.10 \%)$ & $20(64.50 \%)$ & \\
\hline \multirow[t]{2}{*}{ Galactagogue use } & No & $6(60.00 \%)$ & $21(56.75 \%)$ & $22(71.00 \%)$ & \multirow[t]{2}{*}{0.467} \\
\hline & Yes & $4(40.00 \%)$ & $16(43.25 \%)$ & $9(29.00 \%)$ & \\
\hline
\end{tabular}

Abbreviations: $\mathrm{Cl}$, confidence interval; SD, standard deviation.

there was no literature reported regarding the availability of mother's own breast milk based on gestational age stratification for preterm neonates reported from South East Asia. Considering the problematic onset of lactogenesis for preterm mothers during initial postnatal days and average duration to achieve full feeding by 7 to 10 days among VLBW neonates, the seventh day expressed milk volume was chosen as the primary outcome to emphasize the availability of mother's own milk during the need of aggressive enteral nutrition. In a multicentric study, adequacy of milk at 6 weeks was predicted from day 4 milk volume. ${ }^{13}$

Preterm mothers need more multisupportive care for the availability of breast milk compared with term mothers. ${ }^{9}$ Prenatal breastfeeding education is not established except a few baby-friendly hospitals in developing countries for preparedness of milk expression manually or through breast pump within the first hour of infant birth. In Parker et al's study, initiation of milk expression within 1 hour of delivery significantly increased milk volume compared with later ( $>1$ hour) expression. ${ }^{14}$ The frequency and duration of pumping matter along with the timing of initiation for the availability of milk in postdelivery, which is practically difficult in initial stressful days. The availability of breast milk for VLBW neonates depends on the site or unit of care in NICU, representing the role of health care providers in improving breastfeeding. ${ }^{15}$ Duration of NICU stay inversely related to the gestational age of preterm birth and for sustained availability of breast milk, the family should be 


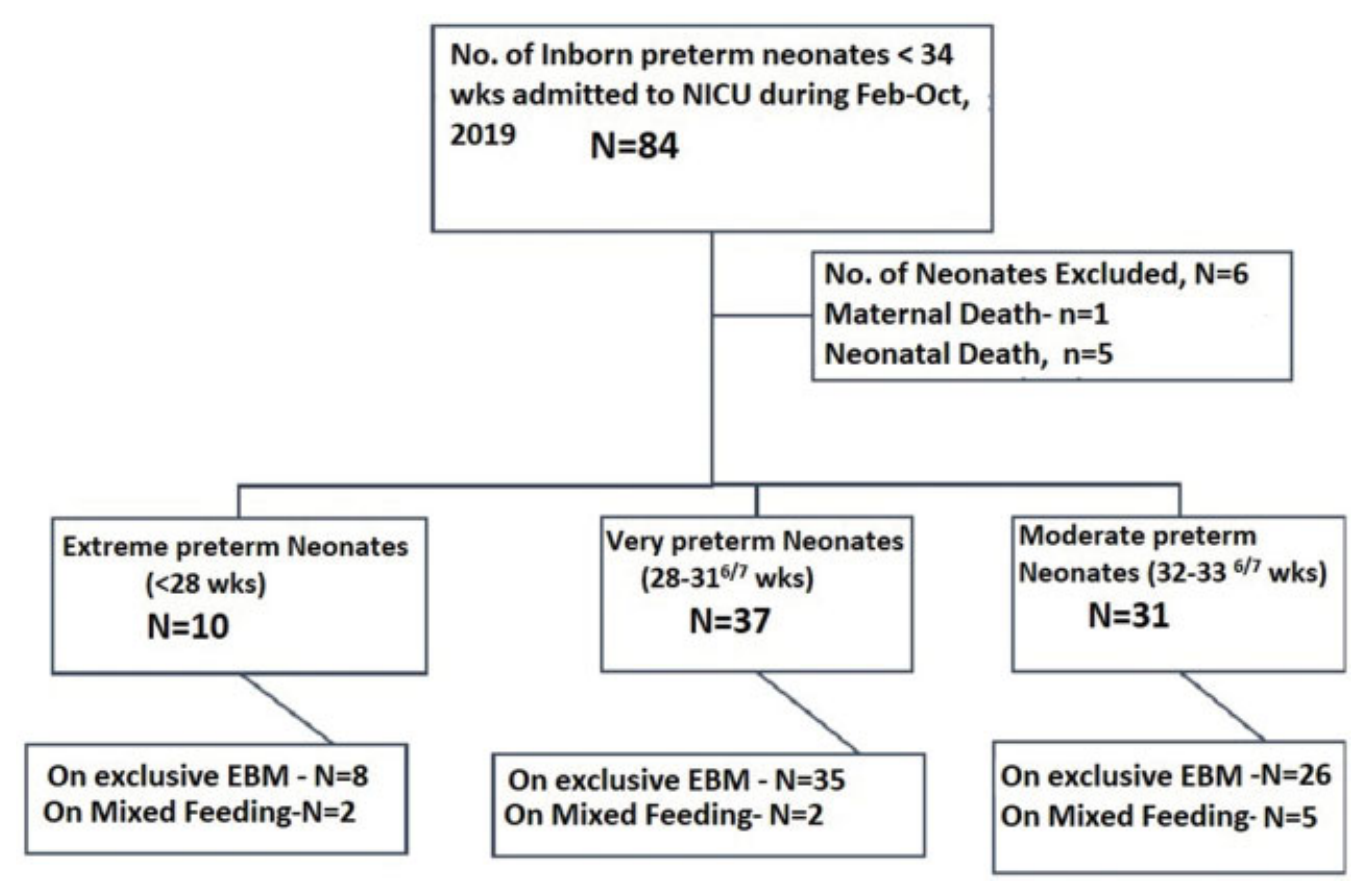

Fig. 1 Receipt of breast milk by the preterm neonates. EBM, expressed breast milk; NICU, neonatal intensive care unit; Mixed Feeding, EBM + formula feeding.

Table 2 Neonatal characteristics stratified by preterm gestational age groups

\begin{tabular}{|c|c|c|c|c|c|}
\hline \multicolumn{2}{|l|}{ Neonatal characteristics } & $\begin{array}{l}\text { Extreme preterm } \\
N=10\end{array}$ & $\begin{array}{l}\text { Very preterm } \\
N=37\end{array}$ & $\begin{array}{l}\text { Moderate preterm } \\
N=31\end{array}$ & $p$-Value \\
\hline \multicolumn{2}{|c|}{ Birth weight $(\mathrm{kg})$, mean $(95 \% \mathrm{Cl}) \pm \mathrm{SD}$} & $0.96(0.80-1.13) \pm 0.23$ & $\begin{array}{l}1.19(1.12-1.25) \pm \\
0.18\end{array}$ & $1.29(1.23-1.36) \pm 0.18$ & $<0.001$ \\
\hline \multirow[t]{2}{*}{ Gender } & Male & $6(60.00 \%)$ & $14(37.80 \%)$ & $15(48.40 \%)$ & \multirow[t]{2}{*}{0.402} \\
\hline & Female & $4(40.00 \%)$ & $23(62.20 \%)$ & $16(51.60 \%)$ & \\
\hline \multirow[t]{2}{*}{ Use of exclusive breast milk } & No & $2(20.00 \%)$ & $2(5.40 \%)$ & $5(16.10 \%)$ & \multirow[t]{2}{*}{0.238} \\
\hline & Yes & $8(80.00 \%)$ & $35(94.60 \%)$ & $26(83.90 \%)$ & \\
\hline \multicolumn{2}{|c|}{$\begin{array}{l}\text { Weight at discharge }(\mathrm{kg}) \text {, mean } \\
(95 \% \mathrm{Cl}) \pm \mathrm{SD}\end{array}$} & $1.90(1.83-1.96) \pm 0.09$ & $\begin{array}{l}1.93(1.84-2.01) \pm \\
0.26\end{array}$ & $1.86(1.67-2.05) \pm 0.52$ & 0.8 \\
\hline \multicolumn{2}{|c|}{$\begin{array}{l}\text { Initiation of feeding }(\mathrm{d}) \text {, median } \\
\text { (IQ1-Q3) }\end{array}$} & $2.5(2-3)$ & $2(2-3.5)$ & $2(1-2)$ & 0.021 \\
\hline \multicolumn{2}{|c|}{ Full feed reached $(\mathrm{d})$ median (Q1-Q3) } & $14.5(10.5-20)$ & $12(9-19)$ & $8(6-10)$ & $<0.001$ \\
\hline \multicolumn{2}{|c|}{$\begin{array}{l}\text { Duration of hospital stay }(\mathrm{d}) \text {, median } \\
\text { (Q1-Q3) }\end{array}$} & $68.5(54-92)$ & $44(33.5-57.5)$ & $27(19-34)$ & $<0.001$ \\
\hline \multicolumn{2}{|c|}{ Duration of KMC (d), median (Q1-Q3) } & $34.5(31-49)$ & $22(16.5-28)$ & $11(8-17)$ & $<0.001$ \\
\hline
\end{tabular}

Abbreviations: $\mathrm{Cl}$, confidence interval; KMC, kangaroo mother care; SD, standard deviation.

supported such as shelter to mother and few family members, KMC practice, nonnutritive sucking, regular family counseling, psychological support, maternal nutrition, and health care. Kangaroo care units were superior in breast milk feeding for preterm neonates in various studies. ${ }^{16-18}$ In this study, all neonates are supported with KMC following the initial sickness period and on average, half of the total hospital days of all preterm neonates are with KMC. Intermittent feed holding secondary to late-onset neonatal sepsis, necrotizing enterocolitis, and prematurity-related feed intolerance are commonly encountered during extreme preterm care, which affects maternal psychology and a major barrier for milk production. The study site was enriched with two dedicated staff nurses for sustained antenatal and postnatal maternal support, daily basis recording of mother's attempt for milk expression, and daily basis milk volume recording which was used as a continuous maternal motivation. 


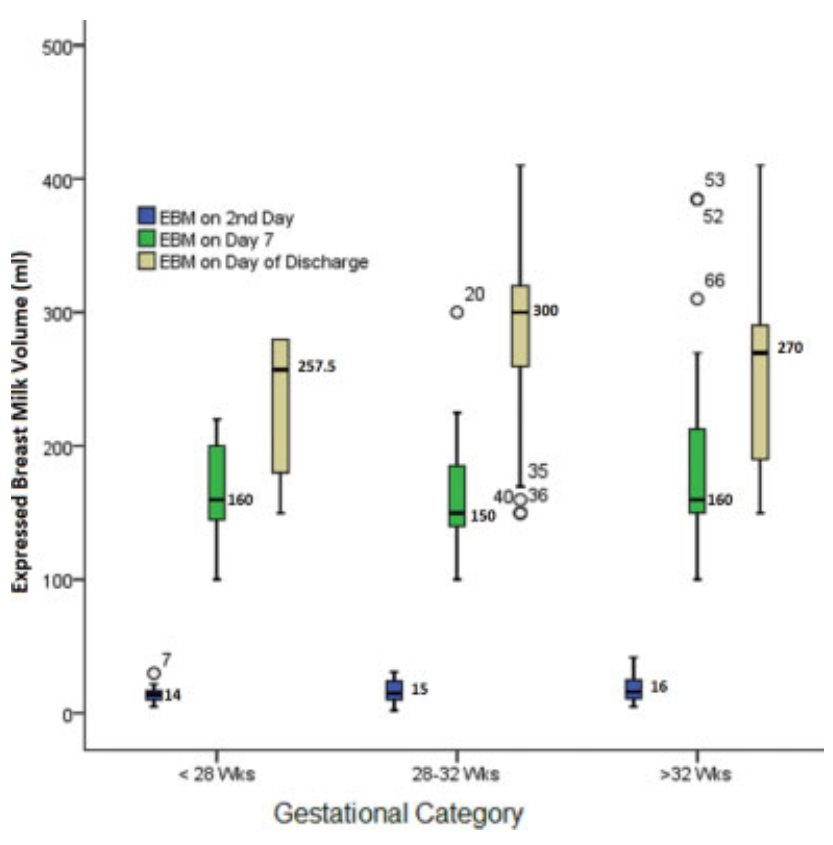

Fig. 2 Box plot showing expressed breast milk (EBM) volume on different postnatal days stratified by gestational age groups.

Table 3 Regression model

\begin{tabular}{|c|c|c|c|}
\hline Variables & $\operatorname{Exp}(B)$ & $95 \% \mathrm{Cl} \operatorname{Exp}(B)$ & $p$-Value \\
\hline \multicolumn{4}{|l|}{ Antenatal steroid } \\
\hline No & \multicolumn{3}{|l|}{1} \\
\hline Yes & 1.39 & $0.504-3.838$ & 0.525 \\
\hline \multicolumn{4}{|l|}{ Mode of delivery } \\
\hline Cesarean section & \multicolumn{3}{|l|}{1} \\
\hline Vaginal delivery & 1.544 & $0.58-4.112$ & 0.384 \\
\hline \multicolumn{4}{|c|}{ Assisted reproductive technique for conception } \\
\hline Yes & \multicolumn{3}{|l|}{1} \\
\hline No & 1.393 & $0.228-8.498$ & 0.719 \\
\hline \multicolumn{4}{|l|}{ Gestational category } \\
\hline Extreme preterm & \multicolumn{2}{|l|}{1} & 0.896 \\
\hline Very preterm & 0.863 & $0.177-4.214$ & 0.855 \\
\hline Moderate preterm & 1.097 & $0.212-5.671$ & 0.912 \\
\hline
\end{tabular}

Abbreviation: $\mathrm{Cl}$, confidence interval.

The enteral nutrition practice for VLBW neonates in this study was congruous to various studies toward the achievement of full enteral feeding by gestational age. ${ }^{4,5}$ From the National Vital Statistics System of United States 2017, the receipt of breast milk varies across gestational age was reported by Chiang et al. The extreme preterm ( $<28$ weeks), early reterm (28-33 weeks), and late preterm received breast milk in $71.3,76.0$, and $77.3 \%$, respectively. ${ }^{19}$ In this study, all inborn preterm neonates during the study period had ingested any breast milk except one neonate with maternal death. Among EPTI, VPTI, and MPTI, the exclusive breast milk ingestion during NICU was 80,94 , and $83 \%$, respectively. In a quality improvement program, through multiple Plan-DoCheck-Act cycles, the availability of EBM by 48 hours had improved from 4.7 to $15.8 \mathrm{~mL}$ and around $82.3 \%$ VLBW neonates were on EBM at the time of attaining $100 \mathrm{~mL} / \mathrm{kg} /$ $\mathrm{d}$ enteral feeding. ${ }^{20}$ The provision of breast milk for preterm neonates in California NICUs was predicted on gestational age and 1-week advancement in gestational age was associated with modest to increase in breast milk feeding at discharge. ${ }^{21}$

Maternal lactogenesis is affected by mode of delivery, maternal medication, and gestational age of delivery. ${ }^{7}$ Cesarean section is found to be a barrier to initiating breastfeeding even in term delivery. ${ }^{8}$ Antenatal corticosteroids have been found to have an effect on reduced breast milk volumes, in particular, in those women who have delivered at the very preterm gestational age and they need more supportive care. ${ }^{9}$ In Enhancing breast milk production with Domperidone in mothers of preterm neonates (EMPOWER) trial, the milk volume produced by mothers between $23^{0 / 7}$ to $-26^{6 / 7}$ and $27^{0 / 7}$ to $29^{6 / 7}$ weeks were not significantly different, and there was no independent influence of mode of delivery and maternal antenatal steroid on EBM volume. ${ }^{22}$ We could not find any research to confirm or refute the link between the mode of conception and EBM volume. In this study, mode of conception, antenatal steroid exposure, and mode of delivery across gestational age groups have nonsignificant effect on the availability of EBM. Data were analyzed from a single tertiary center with a relatively small sample size from neonatal case records and milk diary. The nonavailability of the maternal sociodemographic profile including maternal education is a limitation in this study. Maternal education is a potential contributing factor to the mother's willingness to exclusively breastfeed.

\section{Conclusion}

Mothers of extreme and very preterm neonates expressed milk volume similar to that of moderate preterm neonates at different postnatal days despite physiological barrier and in contrast to usual perception. Therefore, the perinatal team must put coordinated effort for the availability of mother's own milk for all preterm neonates. Further prospective multicentric study on quality improvement on availability of breast milk for preterm neonates $<34$ weeks in a developing country is timely needed.

\section{Conflict of Interest}

None declared.

\section{References}

1 Liu L, Oza S, Hogan D, et al. Global, regional, and national causes of under-5 mortality in 2000-15: an updated systematic analysis with implications for the Sustainable Development Goals. Lancet 2016;388(10063):3027-3035

2 Mangili G, Garzoli E. Feeding of preterm infants and fortification of breast milk. Pediatr Med Chir 2017;39(02):158

3 Rose AT, Patel RM. A critical analysis of risk factors for necrotizing enterocolitis. Semin Fetal Neonatal Med 2018;23(06):374-379 
4 Karagol BS, Zenciroglu A, Okumus N, Polin RA. Randomized controlled trial of slow vs rapid enteral feeding advancements on the clinical outcomes of preterm infants with birth weight 750-1250 g. JPEN J Parenter Enteral Nutr 2013;37(02):223-228

5 Modi M, Ramji S, Jain A, Kumar P, Gupta N. Early aggressive enteral feeding in neonates weighing 750-1250 grams: a randomized controlled trial. Indian Pediatr 2019;56(04):294-298

6 Cregan MD, De Mello TR, Kershaw D, McDougall K, Hartmann PE. Initiation of lactation in women after preterm delivery. Acta Obstet Gynecol Scand 2002;81(09):870-877

7 Sievers E, Haase S, Oldigs HD, Schaub J. The impact of peripartum factors on the onset and duration of lactation. Biol Neonate 2003; 83(04):246-252

8 Evans KC, Evans RG, Royal R, Esterman AJ, James SL. Effect of caesarean section on breast milk transfer to the normal term newborn over the first week of life. Arch Dis Child Fetal Neonatal Ed 2003;88(05):F380-F382

9 Henderson JJ, Hartmann PE, Newnham JP, Simmer K. Effect of preterm birth and antenatal corticosteroid treatment on lactogenesis II in women. Pediatrics 2008;121(01):e92-e100

10 Section on Breastfeeding. Breastfeeding and the use of human milk. Pediatrics 2012;129(03):e827-e841

11 Jahan Y, Rahman A. Human milk banking can be an innovative approach for developing countries. Health Promot Perspect 2018; 8(04):249-251

12 Lau C. Breastfeeding challenges and the preterm motherinfant dyad: a conceptual model. Breastfeed Med 2018;13 (01):8-17

13 Hill PD, Aldag JC. Milk volume on day 4 and income predictive of lactation adequacy at 6 weeks of mothers of nonnursing preterm infants. J Perinat Neonatal Nurs 2005;19(03):273-282
14 Parker LA, Sullivan S, Krueger C, Kelechi T, Mueller M. Effect of early breast milk expression on milk volume and timing of lactogenesis stage II among mothers of very low birth weight infants: a pilot study. J Perinatol 2012;32(03):205-209

15 Powers NG, Bloom B, Peabody J, Clark R. Site of care influences breastmilk feedings at NICU discharge. J Perinatol 2003;23(01): $10-13$

16 Heidarzadeh M, Hosseini MB, Ershadmanesh M, Gholamitabar Tabari M, Khazaee S. The effect of kangaroo mother care (KMC) on breast feeding at the time of NICU discharge. Iran Red Crescent Med J 2013;15(04):302-306

17 Suman RP, Udani R, Nanavati R. Kangaroo mother care for low birth weight infants: a randomized controlled trial. Indian Pediatr 2008;45(01):17-23

18 Almeida Hd, Venancio SI, Sanches MT, Onuki D. The impact of kangaroo care on exclusive breastfeeding in low birth weight newborns. J Pediatr (Rio J) 2010;86(03):250-253

19 Chiang KV, Sharma AJ, Nelson JM, Olson CK, Perrine CG. Receipt of breast milk by gestational age - United States, 2017. MMWR Morb Mortal Wkly Rep 2019;68(22):489-493

20 Thakur A, Kler N, Garg P, Singh A, Gandhi P. Impact of quality improvement program on expressed breastmilk usage in very low birth weight infants. Indian Pediatr 2018;55(09):739-743

21 Lee HC, Gould JB. Factors influencing breast milk versus formula feeding at discharge for very low birth weight infants in California. J Pediatr 2009;155(05):657-62.e1, 2

22 Asztalos EV, Kiss A, da Silva OP, Campbell-Yeo M, Ito S, Knoppert DEMPOWER Study Collaborative Group. Pregnancy gestation at delivery and breast milk production: a secondary analysis from the EMPOWER trial. Matern Health Neonatol Perinatol 2018; $4: 21$ 